\title{
CROSS-SECTIONAL AND LONGITUDINAL OBSERVATION OF CARDIAC ADAPTATION IN STUDENT ATHLETES
}

\author{
Liping $Z_{\text {haO }}{ }^{1}$, Kazuo OGuri $^{1)}$, Yoshiniro $\mathrm{KatO}^{1)}$, Harumi Kawase ${ }^{2)}$, \\ Mitsuru Seishima $^{3)}$ and Toshio Matsuoka ${ }^{1)}$
}

\begin{abstract}
The purpose of this study was to ascertain whether exercise training cardiac adaptation exists in student rugby athletes, to define an adaptive pattern and to observe the student rugby athletics cardiac adaptive process. Subjects consisted of 42 male senior high school student rugby athletes, who participated in sports in junior high school, and a control group of sedentary students from the same senior high school who were matched for age. Student athletes were measured once a year over a three-year period. Left ventricular internal dimension at the end-diastole (LVIDd) and left ventricular posterior wall thickness at the end-diastole (PWT) were both measured by echocardiography. Because all subjects were growing adolescents, allometric scaling data (which is LVIDd/BSA ${ }^{0.5}$ and $\mathrm{PWT} / \mathrm{BSA}^{0.5}$ ) was used for comparison, to preclude the effect of differences in body size on LVIDd and PWT. Cross-sectional comparisons of athletic students with controls were conducted for each of the three senior high school grades, respectively. The data of student athletes during the three-year study was used for longitudinal comparisons. The results of cross-sectional comparisons showed that LVIDd/BSA ${ }^{0.5}$ in a student athlete group consisting of the three grades combined was greater than the corresponding control group $\left(\mathrm{P}<0.05, \mathrm{P}<0.01\right.$, respectively). PWT/BSA ${ }^{0.5}$ in the athletic group was greater than the control group for the third grade level $(P<0.05)$. The results of the longitudinal comparison revealed that no significant differences were present in LVIDd/BSA ${ }^{0.5}$ during the three-year investigation ( $\mathrm{P}>0.05$, respectively). PWT/BSA ${ }^{0.5}$ at the second and third grade level were obviously greater than at the first grade level $(P<0.05$, respectively); however, no difference between the second and third grade levels existed. The results of this present study suggest that regular rugby exercise training during senior high school obviously induced left ventricular posterior wall thickening in the athletic students. An enlarged left ventricular cavity was observed at the first grade level of senior high school and did not significantly change during three years of senior high school.
\end{abstract}

(Jpn. J. Phys. Fitness Sports Med. 2002, $51: 283 \sim 290$ )

key word : rugby, student athlete, LVIDd, PWT, allometric scaling

\section{Introduction}

Regular physical training in athletes induces adaptive structural changes within the heart ${ }^{1 \sim 11}$. A great deal of investigations conducted on both elite and professional adult athletes suggest that cardiac adaptation induced by exercise training is dependent upon the type of exercise undertaken. Isotonic exercise tend to cause an increase in ven. tricular chamber dimensions, with only mild but proportional increase in wall thickness. In contrast, isometric exercise tend to increase wall thickness alone ${ }^{8,12 \sim 18)}$. The majority of previous studies have focused predominantly on the crosssectional investigation of adult professional athletes who participated in various sports. Few studies actually stated initial time of cardiac adaptation following exercise training ${ }^{13,19)}$. Li

\footnotetext{
1) 岐阜大学医学部スポー医・科学講座 于500-8705 岐阜市司町40番地

2) 岐阜大学医学部附属病院中央検査部 テ500-8705 岐阜市司町40番地

3) 岐阜大学医学部臨床検査医学講座 テ500-8705 岐阜市司町40番地
}

\author{
Department of Sports Science and Sports Medicine, Gifu University \\ School of Medicine \\ Central Clinical Laboratory of University Hospital, Gifu University \\ School of Medicine \\ Department of Laboratory Medicine, Gifu University School of \\ Medicine
}


mited information regarding adolescent and longitudinal research is available ${ }^{2,20,21)}$. In this study, echocardiography (which is noninvasive and precise) was used to observe the cardiac structural changes in student athletes who participated in a senior high school rugby team for three years. Cross sectional comparisons with sedentary students and longitudinal comparisons within student athletes during the three year period were conducted. Our purpose was to ascertain whether cardiac adaptation existed in these student rugby athletics and to define a cardiac adaptive pattern, while observing the echocardiography cardiac adaptive process induced by exercise training.

\section{Method}

\section{A. Subjects :}

Study participants consisted of male senior high school athletics and sedentary students as the control group. The student athletes who regularly trained with their school rugby team during all three years of senior high school were selected as athletic student group. The measurements of athletic students were carried out in July 1998, 1999, 2000 and 2001, respectively, once a year. Because some of these student athletes ceased their training or transferred to other schools, in the end, forty-two student athletes' data of continuous three years at the senior high school level was collected. The student athletes that participated in this study had taken part in baseball, tennis and soccer etc. club at their former junior high schools before entering the senior high school level. Dur. ing senior high school, they trained six days every week and three times per day to participate in interscholastic competition.

Control students were selected at the same school and matched for age. The control group consisted of ten male students at the first grade level, six at the second grade level and eight at the third grade level. No control students had formerly or were currently engaged in any regular exercise training associated with competitive sports. The measurements of the control students were conducted in July 2001. The body surface area (BSA) of athletic students was significantly greater than that of the control students. The data of the athletic students during the three year period and the control students is presented in table 1.

Both athletic students and control students voluntarily participated in this study. All subjects were healthy and free of hypertension, heart disease and had no family history of hypertrophic

Table 1. Subjects' characteristics.

\begin{tabular}{|c|c|c|c|c|c|c|}
\hline & \multicolumn{2}{|c|}{ First grade } & \multicolumn{2}{|c|}{ Second grade } & \multicolumn{2}{|c|}{ Third grade } \\
\hline & $\begin{array}{l}\text { Athlete } \\
\mathrm{n}=42\end{array}$ & $\begin{array}{l}\text { Control } \\
n=10\end{array}$ & $\begin{array}{l}\text { Athlete } \\
\mathrm{n}=42\end{array}$ & $\begin{array}{l}\text { Control } \\
n=6\end{array}$ & $\begin{array}{l}\text { Athlete } \\
\mathrm{n}=42\end{array}$ & $\begin{array}{l}\text { Control } \\
\mathrm{n}=8\end{array}$ \\
\hline Age(yr) & $\begin{array}{l}15.92 \\
(0.30)\end{array}$ & $\begin{array}{l}15.91 \\
(0.30)\end{array}$ & $\begin{array}{l}16.78 \\
(0.29)\end{array}$ & $\begin{array}{l}16.68 \\
(0.21)\end{array}$ & $\begin{array}{l}17.78 \\
(0.29)\end{array}$ & $\begin{array}{l}17.84 \\
(0.34)\end{array}$ \\
\hline Height(m) & $\begin{array}{l}1.72^{\star} \\
(0.06)\end{array}$ & $\begin{array}{l}1.67 \\
(0.08)\end{array}$ & $\begin{array}{l}1.73 \\
(0.06)\end{array}$ & $\begin{array}{l}1.67 \\
(0.06)\end{array}$ & $\begin{array}{l}1.73 \\
(0.06)\end{array}$ & $\begin{array}{l}1.71 \\
(0.05)\end{array}$ \\
\hline Weight $(\mathrm{kg})$ & $\begin{array}{l}71.81^{\star \star} \\
(11.46)\end{array}$ & $\begin{array}{l}57.53 \\
(5.24)\end{array}$ & $\begin{array}{l}72.74^{\star \star} \\
(10.84)\end{array}$ & $\begin{array}{l}58.41 \\
(7.32)\end{array}$ & $\begin{array}{l}74.50^{\star *} \\
(11.31)\end{array}$ & $\begin{array}{l}61.49 \\
(10.76)\end{array}$ \\
\hline $\mathrm{BMI}\left(\mathrm{kg} / \mathrm{m}^{2}\right)$ & $\begin{array}{l}24.23^{\star \star} \\
(3.28)\end{array}$ & $\begin{array}{l}20.82 \\
(2.34)\end{array}$ & $\begin{array}{l}24.35^{\star} \\
(3.10)\end{array}$ & $\begin{array}{l}20.85 \\
(2.21)\end{array}$ & $\begin{array}{l}24.81^{\star *} \\
(3.44)\end{array}$ & $\begin{array}{l}20.92 \\
(2.70)\end{array}$ \\
\hline $\operatorname{BSA}\left(\mathrm{m}^{2}\right)$ & $\begin{array}{l}1.84^{\star \star} \\
(0.16)\end{array}$ & $\begin{array}{l}1.64 \\
(0.09)\end{array}$ & $\begin{array}{l}1.86^{\star \star} \\
(0.15)\end{array}$ & $\begin{array}{l}1.65 \\
(0.11)\end{array}$ & $\begin{array}{l}1.88^{* *} \\
(0.15)\end{array}$ & $\begin{array}{l}1.72 \\
(0.16)\end{array}$ \\
\hline
\end{tabular}

Values are mean (SD). ${ }^{*} \mathrm{P}<0.05,{ }^{*} \mathrm{P}<0.01$, significantly different from the control group. Athlete : student athlete. 
cardiomyopathy.

\section{B. Measurements :}

Subjects were instructed to rest for ten minutes before measurements, then the anthropometrical assessment for height $(\mathrm{m})$ and body mass $(\mathrm{kg})$ was performed. The blood pressure was measured by cuff sphygmomanometer. The electrocardiogram was recorded and immediately followed by the echocardiographic measurement (UF-4500, Fukuda electronic stock company). A $3.5 \mathrm{MHZ}$ transducer was used. Criteria of measurement compris ed of LVIDd and PWT. Subjects were taken in the left lateral or supine decubitus position after a clear left ventricle short-axis view at papillary muscle level was taken by B-mode from left parasternal window, M-mode was then used to measure LVIDd and PWT on-line and results were recorded. Both measurements were taken at the end diastole of the left ventricle, according to guidelines recommended by the American Society of Echocardiography ${ }^{22)}$. All measurements were completed by the same experienced physician.

\section{Data analysis :}

Athletic students and control students involved in this study were growing adolescents. With increased in age, their height, weight and heart in creased $^{23 \sim 26)}$. BSA is a combinative criterion of height and weight. Previous investigations sug. gested that a high correlation exists between BSA and cardiac dimension ${ }^{3,26-28)}$. Recent studies showed that one dimension/linear cardiac dimen. sion should be scaled by $\mathrm{BSA}^{0.529 .30)}$. This allometric scaling is useful when we compare the cardiac dimension between different group and different period of the same person. BSA was calculated by the formula of Dubois et al. ${ }^{31}$ ).

The present study adopted cross-sectional and longitudinal comparisons. Cross-sectional comparisons were conducted between athletic students and control students among the first, second and third grade levels, respectively.

Because the athletic student groups and the corresponding control groups were the same age, absolute data of LVIDd and PWT were initially compared. In order to preclude the influence of the difference in BSA, allometric scaling data (which is LVIDd/BSA ${ }^{0.5}$ and $\mathrm{PWT} / \mathrm{BSA}^{0.5}$ ) was used to compare groups of cross-section among the three grades. The unpaired t-test was employed for statistical analysis, and the significant difference was as $\mathrm{p}<0.05$. To observe the altering process of the cardiac adaptation within the student athletes, and to preclude increase in cardiac dimension with growth, longitudinal comparisons were completed using allometric scaling data throughout a three year time period. One-way ANOVA were used for statistical analysis, and $\mathrm{p}<0.05$ was the existing, significant difference.

\section{Results}

A. The absolute cardiac dimension values of LVIDd and PWT in the athletic student group and the control group at the first, second and third grade levels are recorded in table 2. These absolute values show that the LVIDd of all athletic student groups was greater than the control groups among all three grades. The PWT at second and three grade of the athletic student group were greater than the control groups except PWT at the first grade.

B. The LVIDd and PWT values after allometric scaling of the athletic student groups and the control student groups at every grade are presented in table 3 . This data reveals that after precluding the influence of the difference in BSA, the LVIDd/BSA ${ }^{0.5}$ of the athletic student groups was greater than in the control groups throughout all three grades. The $\mathrm{PWT} / \mathrm{BSA}^{0.5}$ between the athletic group and the control group at the first and second grade levels was not significantly different; 
Table 2. The absolute values of LVIDd and PWT in student athlete groups and control groups.

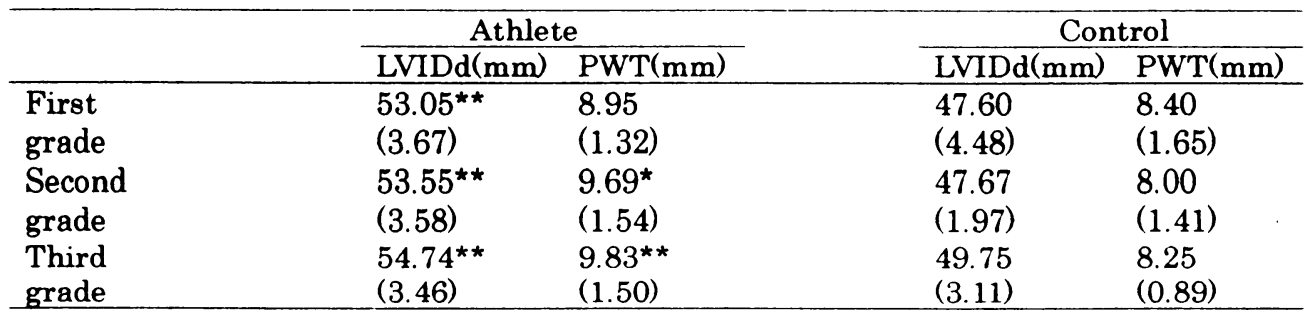

Values are mean $(\mathrm{SD}) .{ }^{*} \mathrm{P}<0.05,{ }^{*} \mathrm{P}<0.01$, significantly different from the control group. Athlete : student athlete.

Table 3. Allometric scaling values of LVIDd and PWT in student athlete groups and control groups.

\begin{tabular}{|c|c|c|c|c|}
\hline & \multicolumn{2}{|c|}{ Athlete } & \multicolumn{2}{|c|}{ Control } \\
\hline & $\mathrm{LVIDd} \mathrm{BSA}^{0.5}$ & $\mathrm{PWT}^{\mathrm{B}} \mathrm{BSA}^{0.5}$ & $\mathrm{LVIDd} / \mathrm{BSA}^{0.5}$ & $\mathrm{PWT} / \mathrm{BSA}^{0.5}$ \\
\hline First & $39.17^{*}$ & 6.61 & 37.17 & 6.58 \\
\hline grade & $(2.61)$ & $(0.93)$ & (3.03) & (1.35) \\
\hline Second & $39.34^{\star}$ & 7.11 & 37.11 & 6.24 \\
\hline grade & $(2.38)$ & $(1.03)$ & $(2.02)$ & (1.15) \\
\hline Third & $39.98^{\star *}$ & $7.18^{\star}$ & 37.99 & 6.31 \\
\hline grade & $(2.45)$ & $(1.04)$ & (1.16) & $(0.70)$ \\
\hline
\end{tabular}

Values are mean (SD). ${ }^{*} \mathrm{P}<0.05,{ }^{*} * \mathrm{P}<0.01$, significantly different from the control group. LVIDd $(\mathrm{mm})$, PWT $(\mathrm{mm})$, BSA $\left(\mathrm{m}^{2}\right)$. Athlete : student athlete.

however, at the third grade level, the $\mathrm{PWT} / \mathrm{BSA}^{0.5}$ of the athletic group was greater than that of control group.

C. Longitudinal comparisons were conducted among the three grades of the athletic student groups. There were no significant differences in LVIDd/BSA ${ }^{0.5}$ among three grades, as illustrated in fig 1. The PWT/BSA ${ }^{0.5}$ at the first grade level was significantly less than among athletes in the second and third grade levels; however, no differences existed between these two grades. These results suggest that the left ventricular posterior wall of athletic students obviously thickens sometime between first and second grade.

\section{N. Discussion}

Many aspects of human structural dimensions are influenced by body size $\mathrm{e}^{30}$. BSA is a combina- tion height with weight measurement and is therefore frequently used as a criterion for proper body size reflection. When comparing inter-group

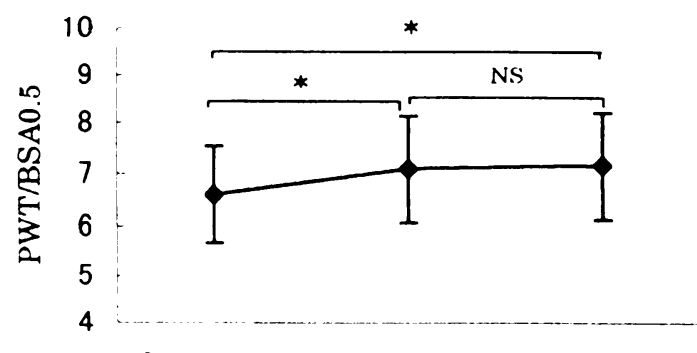

first grade second grade third grade

Time

Fig. 1. The changes of $\mathrm{PWT} / \mathrm{BSA}^{0.5}$ in student athlete during thrre grades.

Values are means \pm SD. NS : not significant. ${ }^{*}$ : significant difference, $\mathrm{P}<0.05$. BSA0.5: $\mathrm{BSA}^{0.5}$ $\operatorname{LVIDd}(\mathrm{mm}), \operatorname{BSA}\left(\mathrm{m}^{2}\right)$. 
and inter-individual, the ratio of linear cardiac dimension to BSA (e.g. LVIDd/BSA, PWT/BSA) was used for many previous investigations of athletes' hearts to preclude the impact of difference in body size. Recent studies show that a nonlinear relationship exists between the onedimensional cardiac structure and the body size variable $e^{30,32,33)}$ and that one-dimension/linear cardiac dimension should be scaled by $\mathrm{BSA}^{0.529 .30)}$. This allometric scaling approach is supported by the studies of George et al. ${ }^{30)}$, Simone et al. ${ }^{34)}$, and Batterham et al. ${ }^{35)}$. The athletic students and control students participated in present study were growing adolescents. Their height, weight and cardiac size increased with growth ${ }^{23-26)}$. Therefore, allometric scaling criteria (which is LVIDd/BSA ${ }^{0.5}$ and PWT/BSA ${ }^{0.5}$ ) was employed for cross-sectional and longitudinal comparisons.

In the isotonic (endurance) athlete, owing to chronic volume overload, the size of the left and right ventricular cavities increase, with prop. ortional increase in septal and free-wall thickness. In the isometric (weight) athlete, due to chronic pressure overload, septal and free-wall thickness increases, with little or no increase in left ventricular end-diastolic diameter. Many athletic endeavors are a combination of isometric and isotonic work and thus may produce a combination of morphologic pat. terns $3.7,12 \sim 14,16,18,21)$. These conclusions are supported by many researches of adult elite athletes $^{1.3 \sim 6.8 \sim 11.13 \sim 17)}$.

Allen et al. ${ }^{2)}$ assessed 77 swimming subjects aged 5 to 17 years and observed that the PWT exceed the 95 th percentile in $62(81 \%)$. Somauroo et al. $^{21)}$ investigated 171 soccer player aged 15.3 to 18.3 years. Both LVIDd and PWT in the soccer players were significantly increased when com. pared with either age matched or BSA matched control data. Roeske et al. ${ }^{1)}$ compared 42 profes- sional male basketball athletes with controls matched for age, sex, height, weight and BSA and showed that the LVIDd and PWT of athletes were obviously greater than among the controls. George et al. ${ }^{29)}$ investigated alpine skier athletes by allometric scaling data. Their results revealed that both the LVIDd/BSA ${ }^{0.5}$ and the PWT/BSA ${ }^{0.5}$ of athletes were significantly greater than among the controls. The athletic students involved in this study took part in soccer, baseball and tennis etc. club during their junior high school years. Thus, the cross-sectional comparisons show the LVIDd/BSA ${ }^{0.5}$ of all three grades' athletic groups were greater than that of the control groups. The $\mathrm{PWT} / \mathrm{BSA}^{0.5}$ of the student athletes in third grade was greater than the controls. These results suggest that precluding the impact of difference in body size, regular rugby training induced left ventricular posterior wall thickening of the athletic students during senior high school. Left ventricular cavity enlargement could be attributed to various disciplines during both junior high school and senior high school.

Onishi et al. ${ }^{20)}$ longitudinally observed 16 athletes from 18 to 21 years who did not change height and weight. Increase in LVIDd was seen prior to an increase in PWT. In this study, the longitudinal comparisons of LVIDd/BSA ${ }^{0.5}$ and $\mathrm{PWT} / \mathrm{BSA}^{0.5}$ among the three grade levels were conducted. There were no significant differences in $\mathrm{LVIDd} / \mathrm{BSA}^{0.5}$ among the three grades levels. Enlarged left ventricular cavities of the athletes at the first grade level who had participated in sports club during respective junior high school did not significantly change during senior high school. PWT/BSA ${ }^{0.5}$ at the second and three grade level were obviously greater than at the first grade level. No difference between second grade and third grade was observed. That is, the

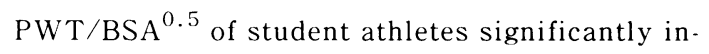
creased from the first to second year during the 
senior high school period. These results reveal that precluding influence of growth, regular rugby training during senior high school induced left ventricular posterior wall thickening in the athletic students.

In summary, the results of this study suggest that regular rugby exercise training during senior high school obviously induced left ventricular posterior wall thickening among the athletic students. An enlarged left ventricular cavity was observed at the first grade level of senior high school and did not significantly change during the three years of senior high school.

\section{Acknowledgements}

The authors wish to thank all the members of the staff who participated in this study, as well as the many volunteer subjects for their cooperation.

(Accepted Feb. 18, 2002)

\section{References}

1) Roeske, W. R., O’Rourke, R. A., Klein, A., Leopold, G. and Karliner, J. S. Noninvasive evaluation of ven. tricular hypertrophy in professional athletes. Cir. culation. (1976), $53: 286-292$.

2) Allen HD, Goldberg SJ, Sahn DJ, Schy N, and Wojcik R. A quantitative echocardiographic study of champion childhood swimmers. Circulation. (1977), 55 : 142-145.

3) Spirito, P., Pelliccia, A., Proschan, M. A., Granata, M., Spataro, A., Bellone, P., Caselli, G., Biffi, A., Vecchio, C. and Maron, B. J. Morphology of The, athlete's heart 'assessed by echocardiography in 947 elite athletes representing 27 sports. The American Journal of Cardiology, (1994), 74 : 802-806.

4) Shapiro LM. Physiological left ventricular hypertro phy. Br. Heart. J. (1984), 52 : 130-135.

5) Raskoff, W. J., Goldman, S. and Cohn, K. The 'athletic heart'. Prevalence and physiological significance of left ventricular enlargement in distance runners. JAMA., (1976), 236 : 158-162.

6) Bekaert, I., Pannier, J. L., Weghe, C. V. D., Durme, J. P. V., Clement, D. L. and Pannier, R. Non-invasive evaluation of cardiac function in professional cyc. lists. Br. Heart., (1981), 45 : 213-218.

7) Lengyel, M. and Gyarfas, I. The importance of echocardiography in the assessment of left ventricular hypertrophy in trained and untrained schoolchil. dren. Acta. Cardiologica., (1979), 34 : 63-69.
8) Demaria, A. N., Neumann, A., Lee, G., Fowler, W. and Mason, D. T. Alteration in ventricular mass and performance induced by exercise training in man evaluated by echocardiography. Circulation. (1978), 57 : 237-244.

9) Oakley, G. D. G. The athletic heart. Cardiology Clinics, (1987), $5: 319-329$.

10) Rost, R. The athlete's heart. European Heart Jour. nal, (1982), 3 : 193-198.

11) Fagard R, Aubert A, Lysens R, Staessen J, Vanhees $\mathrm{L}$, and Amery A. Noninvasive assessment of seasonal variations in cardiac structure and function in cyclists. Circulation. (1983), $67: 896-901$.

12) Wight JN, and Salem D. Sudden cardiac death and the ' athlete's heart '. Arch. Intern. Med., (1995), $155: 1473-1480$.

13) Maron, B. J. Structural features of the athletic heart as defined by echocardiography. JACC., (1986), 7 : 190-203.

14) Fisher, A. G., Adams, T. D., Yanowitz, F. G., Ridges, J. D., Orsmond, G. and Nelson, A. G. Noninvasive evaluation of world class athletes engaged in dif. ferent modes of training. The American Journal of Cardiology, (1989), $63: 337-341$.

15) Huston, T. P., Puffer, J. C. and Rodney, W. M. The athletic heart syndrome. The New England Journal of Medicine. (1985), 313:25-33.

16) Morganroth J, Maron BJ, Henry WL, and Epstein SE. Comparative left ventricular dimensions in trained athletes. Annals of internal medicine. (1975), $82: 521-524$.

17) Pelliccia A, Maron BJ, Spataro A, Proschan MA, and Spirito $P$. The upper limit of physiologic cardiac hypertrophy in highly trained elite athletes. N. Engl. J. Med. (1991), 324 : 295-301.

18) George KP, Batterham AM, and Jones B. Echocardiographic evidence of concentric left ventricular enlargement in female weight lifters. Eur. J. Appl. Physiol. (1998), 79 : 88-92.

19) Ehsani, A. A. Loss of cardiovasular adaptations after cessation of training. Cardiology Clinics. (1992), $10: 257-266$.

20) Onishi SH. Cross-sectional and longitudinal changes of left ventricular geometry and function in collegi. ate athletes. Journal of keio medical society. (1993), $70: 549-559$.

21) Somauroo JD, Pyatt JR, Jackson M, Perry RA, and Ramsdale DR. An echocardiographic assessment of cardiac morphology and common ECG findings in teenage professional soccer players: reference ranges for use in screening. Heart. (2001), 85 : 649654.

22) Sahn DJ, Maria AD, Kisslo J, and Weyman A. Re. commendations regarding quantitation results of a survey of echocardiographic measurements. Circula. tion. (1978), $58: 1072-1082$. 
23) Huwez FU, Houston AB, Watson J, Mclaughlin S, and Macfarlane PW. Age and body surface area related normal upper and lower limits of $M$ mode echocardiographic measurements and left ventricular volume and mass from infancy to early adult. hood. Br. Heart J. (1994), 72 : 276-280.

24) Nagasawa, H., Arakaki, Y., Yamada, O., Nakajima, T. and Kamiya, T. Longitudinal observation of left ventricular end-diastolic dimension in children using echocardiography. Pediatr. Cardiol., (1996), 17 : 169-174.

25) Epstein ML, Goldberg SJ, Allen HD, Konecke L, and Wood J. Great vessel, cardiac chamber, and wall growth patterns in normal children. Circulation. (1975), $51:$ 1124-1129.

26) Henry WL, Gardin JM, and Ware JH. Echocardiog raphic measurements in normal subjects from infan cy to old age. Circulation. (1980), 62 : 1054-1061.

27) Gutgesell HP, and Rembold CM. Growth of the human heart relative to body surface area. Am. J. Car. diol. (1990), $65: 662-668$.

28) Henry WL, Ware J, Gardin JM. Hepner SI, Mckay J. and Weiner M. Echocardiographic measurements in normal subjects. Circulation. (1978), 57 : 278-285.

29) George Kp, Gates PE, Whyte G, Fenoglio RA, and Lea R. Echocardiographic examination of cardiac structure and function in elite cross trained male and female alpine skiers. Br. J. Sports Med. (1999),
33 : 93-99.

30) George KP, Batterham AM, and Jones B. The impact of scalar variable and process on athlete-control comparisons of cardiac dimensions. Med.Sci. Sports Exerc. (1998), $30: 824-830$

31) Dubois D, and Dubois EF. A formula to estimate the approximate surface area if height and weight be known. Arch.Int. Med. (1916), 17 : 863-871.

32) Batterham AM, and George KP. Modeling the influ. ence of body size and composition on $\mathrm{M}$-mode echocardiographic dimensions. Heart Circ. Physiol. (1998), $43: 701-708$.

33) George K, Sharma S, Batterham A, Whyte G, and Mckenna W. Allometric analysis of the association between cardiac dimension and body size variables in 464 junior athletes. Clinical Science. (2001), 100 : 47-54.

34) Simone GD. Devereux RB, Daniels SR, Koren MJ, Meyer RA, and Laragh JH. Effect of growth on variability of left ventricular mass: assessment of allometric signals in adults and children and their capacity to predict cardiovascular risk. J. Am. Coll. Cardiol. (1995), 25 : 1056-1062.

35) Batterham AM, George KP, and Mullineaux DR. Allometric scaling of left ventricular mass by body dimensions in males and females. Med. Sci. Sports Exerc. (1997), 29 : 181-186. 